Marquette University

e-Publications@Marquette

$2-1-1983$

Supervised Versus Independent Student Laboratories

Luther C. Kloth

Marquette University, luther.kloth@marquette.edu

Mary Ann Morrison

Marquette University

Published version. Physical Therapy, Vol. 63, No. 2 (February 1983): 225-228. DOI. (C) 1983 American Physical Therapy Association. Used with permission. 


\title{
Supervised Versus Independent Student Laboratories
}

\author{
LUTHER C. KLOTH \\ and MARY ANN MORRISON
}

\begin{abstract}
The purpose of this study was to determine if classroom laboratory time could be reduced in a basic physical agents course. Fifty-seven junior physical therapy students were randomly assigned to three laboratory sections. All students received identical lectures, demonstrations, course materials, and laboratory manuals. The control group, Section 1 , received supervision and assistance during laboratory practice. Students in Section 2 and Section 3 worked independent of instructor supervision but could receive assistance from the instructor in an adjacent room. Students in Section 2 were provided with feedback following periodic assessment by the instructor. Attitudinal questionnaire responses indicated that the students preferred the supervised laboratory section. The presence of the instructor during classroom laboratory practice of basic physical agents did not affect student performance. Comparison of written and practical examination results indicated no significant differences in student performance. Classroom laboratory time for faculty and students was reduced when students worked independently.
\end{abstract}

Key Words: Curriculum, Education, Physical therapy.

The increase in the body of knowledge relevant to the physical therapy profession in the recent past has created a time management problem for physical therapy educators. Continual additions of content to curricula have required more efficient use of time by faculty and students during entry-level preparation.

Szumski stated in 1969 that inappropriate use of time was evident in physical therapy undergraduate educational programs. ${ }^{1} \mathrm{He}$ indicated that time was wasted by needless repetition of students practicing techniques on one another in the classroom laboratory.

Previous studies in physical therapy education indicate that student performance was simitar when experimental and control groups had different amounts of practice time. Asklund et al allowed an experimental group to work independently and to be able to choose the amount of time necessary to practice procedures." Campbeil and Kohil's study provided an experimental group with two hours of in-

Mr. Kloth is Associate Professor, Program in Physical Therapy, Marquette Universily, Milwaukee, WI 5,3233 (USA).

Miss Morrison is Associate Professor and Academic Coordinator of Clinical Education. Program in Physical Therapy, Marquette University, Milwaukee, WI 53233.

This articte was submitted April 12, 1982, and accepted Seprember 28. 1982 structor-supervised laboratory practice and a control group with six hours of practice. Both studies demonstrated that individualized learning through the use of slide and tape sessions is less time-consuming but equally effective as the traditional lecture and laboratory method of learning.

Fisher and associates studied first-year medical students who were provided with laboratory experience in neufoanatomy without instructor supervision. ${ }^{4}$ Self-instructional laboratory stations were developed where the student used human specimens to formalate an answer to questions. The laboratory station concept proved economical with respect to both student and instructor time.

This study compares the effectiveness of varying amounts of instructor supervision to determine if classroom laboratory time could be reduced in a basic physical agents course. If physical therapy students can learn to perform basic procedures independent of supervision in the laboratory, the instructor would gain time for scholarly pursuits or other endeavors. Furthermore, the student would have the option of practicing procedures as needed and would also have additional time for other activities. In our program we traditionally provided appropriate theory, demonstrations, and supervised classroom laboratory practice before allowing the student to perform pro- 
cedures on patients. We believed that supervised classroom laboratory practice was a necessary step in the sequence of learning skills. We expected that students who received instructor supervision and assistance during two hours of classroom laboratory practice each week would score higher on written and practical examinations than students who practiced the same procedures without supervision and assistance.

\section{METHOD}

Fifty-seven junior physical therapy students were randomly assigned to one of three classroom laboratory sections in the Physical Agents I course. On the first day of lecture the instructor explained that the three classroom laboratory sections would be structured with minimal differences and that all students wotld meet the same outcome objectives. All students attended lectures and demonstrations and took the same written and practical examinations. The students did not have prior clinical experience. Each student received a laboratory manual, which contained 41 simulated patient situations based on the following nine major physical therapy procedures taught in the course: massage, infrared, hydrotherapy, ultraviotet, shortwave diathermy, microwave diathermy, ultrasound, and cervical and lumbar traction. Patient situations in the physical agents laboratory manual dealt with referral, diagnosis, description of the patient, and any contraindications. Each situation required role playing in performing the simuiated patient treatment. All patient situations had an accompanying task analysis that provided a sequence of weighted steps to use in performing the treatment procedures.

The student was required to evaluate the patient (laboratory partner) and record results. Each situation allowed the student to make decisions about patient positioning and correct equipment or technique to use in performing the treatment. Most situations included the performance of simple exercise routines and instructions for home programs. Thus, the intent was to direct the student toward viewing the whole patient treatment and not just the modality itself.

Before each classroom laboratory session the course instructor performed a demonstration of the procedures to be practiced that day and answered all questions. Instructions to each laboratory section were identical except for the additional requirement for students in Section 2 that they make appointments with the instructor during laboratory time to demonstrate their correct performance of the nine different procedures taught in the course.

The major difference in the three classroom laboratory sections was in the amount of supervision provided by the instructor. Section I consisted of 19 students who participated in two hours a week of instructor-supervised laboratory practice. The 18 students in Section 2 and the 20 students in Section 3 did not have direct instructor supervision during their laboratory sessions. These students were encouraged to practice the situations on one another, and the instructor was available in an adjacent room as a resource person to provide assistance as requested.

Three practical examinations were scheduled dur. ing the semester. Each practical examination was 20 minutes long. To prepare for the first practical examination, the student was asked to review all patient situations that had been demonstrated previously by the instructor. The examiner then randomly chose one situation for each student from the assigned list. A check mark was made after each correcl step that the student performed in the task analysis. Each step had a predetermined numerical value. Thas, at the end of the practical examination a score could be obtained by adding the total points earned. The grade and performance was discussed with the student immediately after the practical examination. To ptevent bias, seven locat physical therapy clinicians served as examinets rather than the course instructor. The examiners had from three to five years of clinical experience and did not know the students or the design of the experiment.

Four written objective examinations were administered during the semester, and two additional questionnaires concerning the course were given to all students. The first questionnaire contained general questions about the course and was completed by the students approximately eight weeks into the semester. A folkow-up questionnaire was administered midway through the subsequent semester. Chi-square was used to test the significance of responses.

Contingency plans for remedial work were outlined in the event that any students demonstrated unacceptabie performance.

All examination scores were subjected to analysis of variance to determine if statistical differences existed in the performance of the students in the three sections.

\section{RESULTS}

Analysis of variance demonstrated no difference in the performance of the students in the three sections on all examinations. The Table illustrates that none of the $F$ ratios were significant at the .05 level.

On both attitudinat questionnaires, students in Section 3 did not rate the overall quality of the course as high as students in the other two laboratory sections. Twelve students in Section 2 indicated that the stpervision they received was sufficient, whereas 16 
TABLE

Means, Standard Deviations, and Analysis of Variance of Results of Written and Practical Examinations in a Physical Agents Course

\begin{tabular}{|c|c|c|c|c|c|c|}
\hline Examination ${ }^{\mathrm{a}}$ & $\bar{x}$ & $s$ & SS & MS & $d f$ & $F$ \\
\hline 1st practical & & & 67.53 & 33.76 & 2 & 1.20 \\
\hline Section 1 & 91.47 & \pm 5.57 & 1512.52 & 28.01 & 54 & \\
\hline Section 2 & 92.11 & \pm 6.20 & 1580.04 & & & \\
\hline Section 3 & 94.00 & \pm 4.10 & & & & \\
\hline 2nd practical & & & 21.06 & 10.53 & 2 & 0.43 \\
\hline Section 1 & 95.79 & \pm 3.75 & $1324.0 t$ & 24.54 & 54 & \\
\hline Section 2 & 94.33 & \pm 4.34 & 1345.96 & & & \\
\hline Section 3 & 94.75 & \pm 6.29 & & & & \\
\hline 3ғd practical & & & 8.09 & 4.05 & 2 & 0.21 \\
\hline Section 1 & 94.63 & \pm 4.42 & 1064.07 & 19.70 & 54 & \\
\hline Section 2 & 95.56 & \pm 5.72 & 1072.16 & & & \\
\hline Section 3 & 95.20 & \pm 2.86 & & & & \\
\hline Written final & & & 37.82 & 16.41 & 2 & 0.55 \\
\hline Section 1 & 86.79 & \pm 4.73 & 1597.30 & 29.58 & 54 & \\
\hline Section 2 & 85.94 & \pm 6.43 & 1630.12 & & & \\
\hline Section 3 & 87.80 & \pm 5.08 & & & & \\
\hline
\end{tabular}

section 1, $n=19 ;$ section $2, n=18$; Section $3, n=20$.

students in Section 3 responded that their supervision was not sufficient $(\rho<.01)$. One-half of Section 3 indicated that they would have preferred being in either of the other laboratory sections, and over 90 percent of the students in Sections 1 and 2 indicated that they were satisfied with the manner in which their laboratory sessions were conducted.

The students in Section 1 who received constant supervision practiced the patient situations for the entire two-hour laboratory session each week. Students in Sections 2 and 3 remained in the classroom laboratory between 1 and 1.5 hours a week.

\section{DISCUSSION}

The amount of instructor supervision did not significantly infuence student performance in a basic physical agents course.

The students' preference for the supervised laboratory section as indicated by the responses on the attitudinal questionnaire may reflect their previous high school and coilege laboratory experiences which most likely provided them with more structure, that is, instructor supervision and assistance. The students' attitude toward the course appeared to correlate positively with the amount of supervision they received and negatively with the independence imposed on them. Further explanation of their attitude may be related to their learning style preferences. Payton et al studied the learning styles of physical therapy students in the United States and found that they prefer to work closely with the instructor and are not inclined to independent action or working alone." Our study concurs with these findings. Similar findings were reported by Rezler and French in 1975 using the Learning Preference Inventory. ${ }^{6}$ The majority of allied health students tested showed a preference for learning in a teacher-directed class.

The students in Section 2 who did not have instructor supervision but were required to demonstrate correct performance of the nine patient situations were satisfied with the manner in which their laboratory sessions were conducted. Their favorable attitude may have resulted from their interaction with and resultan feedback from the instructor during those performance sessions.

In prior years, the physical agents course instructor spent approximately 96 hours during the semester directly supervising students in the classroom laboratory. This study suggests that much of that time could be devoted to schotariy pursuit, classroom preparation, or other endeavors. The instructor who served as a resource person to students in Sections 2 and 3 indicated that he spent approximately one-half of his time answering student questions or expiaining procedures. Thus, the physical agents course instructor could gain 48 hours a semester.

The results of this study suggest that further investigation of the amount of supervision and required practice in classroom laboratories should be pursued. The 1980 American Physical Therapy Association Environmental Statement on educational trends suggests that "educators will become increasingly critical of present modes of learning experiences." "Providing supervised classroom labotatory practice is one mode of learning that is traditionaliy used in physical therapy entry-level education. Perhaps the time spent in classroom laboratories could be curtailed requiring the student to be responsibie for any needed practice before clinical application. 


\section{CONCLUSIONS}

The results of this study indicate that time can be reduced for faculty and students in a basic physical agents classroom laboratory. Students who received instructor supervision of their classroom laboratory practice did not score higher on written and practical examinations than students who worked independent of instructor supervision.

\section{REFERENCES}

1. Szumski Av: Common education for health related personnel: Changing needs in physical therapy education. Ann NY Acad Sci, 166:1017-1019,1969

2. Asklund S, Brown S, Fiterman C: Slide-tape versus lecture demonstration presentation of thermal agents in a physical therapist assistant program. Phys Ther 56:1361-1364, 1976

3. Campbell SK, Kohli MA: Audio-tutorial independent study of goniometry. Phys Ther 50:195-200, 1970
4. Fisher LJ, Davis WK, Hitch EJ, et al: Teaching of Neurcanatomy by means of selt-instructional laboratory stations. Med Ed 14:119-123, 1980

5. Payton O, Hueter A, McDonald M: Learning style prefeqences: Physical therapy students in the United States. Phys Ther 59:147-152, 1979

6. Rezler A, French R: Personality types and learning preferences of students in six allied health professions. Allied Health 4:20-26, 1975

7. Environmental Statement: Vill Educational Trends. in: House of Delegates Handbook. Washington, DC. American Physical Therapy Association, 1980, pp 22-27 